\title{
IMÁGENES RUPESTRES Y MODELOS ARQUEOLÓGICOS. HACIA UNA CONTEXTUALIZACIÓN DE LOS PETROGLIFOS EN LA CUENCA DEL CURI-LEUVÚ. NORTE DE NEUQUÉN, PATAGONIA ARGENTINA
}

\author{
ROCK ART IMAGES AND ARCHAEOLOGICAL MODELS. TOWARDS A \\ CONTEXTUALIZATION OF THE PETROGLYPHS IN THE CURI-LEUVÚ BASIN. \\ NORTH OF NEUQUÉN, ARGENTINE PATAGONIA
}

Fernando Emmanuel Vargas ${ }^{1}$

\begin{abstract}
En este trabajo se presentan nuevos datos de sitios con grabados rupestres de la Cuenca del Curi-Leuvú, norte de la provincia de Neuquén, Argentina, y se los discute a partir de los modelos arqueológicos propuestos para la región en diferentes escalas espaciales. De este modo, integramos la evidencia rupestre dentro de los planteos generales sobre el uso del espacio en el norte de Neuquén, como también avanzamos hacia la contextualización de la producción rupestre por medio de un análisis comparativo con los motivos presentes en sitios conocidos para la cuenca alta del Río Neuquén y el extremo sudeste de la región del Maule, en Chile. Los resultados muestran que los grupos humanos que habitaron la Cuenca del Curi-Leuvú durante el Holoceno Tardío, si bien estructuraron su producción rupestre de forma particular, participaron activamente de una dinámica regional de producción y circulación de códigos visuales e información compartida en el noroeste de Neuquén.
\end{abstract}

Palabras claves: norte de Neuquén, grabados rupestres, códigos visuales, modelos arqueológicos.

In this paper we present new data of sites with engraved rock art in the Curi-Leuvú basin, north of Neuquén Province, Argentina, and discuss them through the archaeological models proposed for the region at different spatial scales. In this way, we integrate the rock art evidence within the general approaches on the use of space in northern Neuquén, and propose a contextualization of rock art production through a comparative analysis with the previously known sites for the high basin of the Neuquén River and the southeast end of the Maule region in Chile. The initial results show that, although they structured their rock art production in a particular way, the human groups that inhabited the Curi-Leuvu Basin during the Late Holocene actively participated in a regional dynamics of production and circulation of shared visual codes and information in the northwest of Neuquén.

Key words: North of Neuquén, engraved rock art, visual codes, archaeological models.

El presente trabajo tiene como objetivo principal dar a conocer nuevos relevamientos de sitios con petroglifos en la cuenca media del Curi-Leuvú y discutirlos a la luz de las expectativas generadas por los modelos arqueológicos propuestos para el norte neuquino (Barberena 2013; Barberena et al. 2017; Hajduk y Lezcano 2007). De este modo, se espera contribuir a la discusión sobre los modos de uso del espacio e interacción social en la región, así como también dilucidar bajo que características se estructuró la producción rupestre, y de qué modo y alcance, circularon estos códigos visuales a distintas escalas espaciales.

Actualmente, si bien los estudios rupestres en el norte de Neuquén se han integrado definitivamente dentro de programas de investigación arqueológicos que abordan procesos en escalas temporales y espaciales amplias, existe una ausencia de rangos cronológicos asignables a los diferentes contextos de producción rupestre. Esta situación dificulta

\footnotetext{
${ }^{1}$ Instituto de Investigaciones en Diversidad Cultural y Procesos de Cambio (IIDyPCa - CONICET - UNRN). San Carlos de Bariloche, Río Negro, Argentina. femmanuelvargas@gmail.com
} 
discutir la variabilidad y la recurrencia de las imágenes visuales en función de las dinámicas de cambio de los grupos humanos en el pasado.

En este marco, este trabajo se propone comenzar a contextualizar los grabados del Curi-Leuvú a partir de un análisis comparativo de la producción visual rupestre, priorizando un abordaje estrictamente espacial en dos escalas. Por un lado, en el espacio circunscrito a la Cuenca del Curi-Leuvú, donde analizamos cómo se estructura el registro rupestre grabado explorando cualitativa y cuantitativamente diferencias entre los sitios en función de su localización en el espacio, disponibilidad de soportes, técnicas empleadas y tipos de motivos. Por otro a una escala regional, efectuamos un primer análisis comparativo con los sitios rupestres grabados localizados en la cuenca alta del río Neuquén y la Cuenca del Cajón del Valdez, en el extremo sudeste de la región del Maule en Chile (Figura 1). Esta comparación se efectúa sobre la base de la similitud morfológica de los tipos y grupos de motivos, retomando clasificaciones previas.

Los resultados iniciales nos permiten corroborar las expectativas propuestas por los modelos arqueológicos, así como también delinear algunas tendencias generales sobre la producción rupestre. En este sentido, los grupos humanos que habitaron la cuenca del Curi-Leuvú durante el Holoceno Tardío, si bien estructuraron su producción rupestre de forma particular en función de su emplazamiento a diferentes cotas y con una mayor variabilidad de motivos, participaron activamente de una dinámica regional de producción y circulación de códigos visuales e información compartida en el noroeste neuquino.

\section{Marco Geográfico y Ambiental}

Nuestra área de estudio se ubica en la cuenca media del Curi-Leuvú, al este de la Cordillera del Viento (Figura 1). Esta formación se localiza a unos 50 $\mathrm{km}$ al este de la Cordillera de los Andes y se extiende en sentido norte-sur por cerca de $70 \mathrm{~km}$. La cordillera del Viento presenta alturas promedio del orden de los $3.000 \mathrm{msm}$ y actúa como divisoria geográfica natural del norte de Neuquén, que separa la cuenca del rio Neuquén hacia el oeste y la cuenca del rio Curi-Leuvú hacia el este (Figura 1).

En términos geográficos, en las nacientes del Río Curi-Leuvú la topografía es accidentada con importantes elevaciones montañosas, que en el extremo norte se unen con la ladera sur del Volcán Domuyo (4.707 m). Contrariamente, en los tramos medios y bajos de la cuenca, el paisaje es menos abrupto, en particular el faldeo este de la Cordillera del Viento donde las pendientes son más suaves y se extienden hasta llegar al valle del mismo río. Esta situación de marcado desnivel entre valles intermontanos altos y accidentados en las nacientes de ríos y arroyos, con pendientes más suaves y abiertas sobre los faldeos de las montañas, se corrobora también en la Cuenca del Río Neuquén, configurando así en todo el norte de Neuquén un paisaje de fuerte variación topográfica (Barberena et al. 2017) y la presencia de diferentes pisos altitudinales (Cuneo 2017).

Específicamente, el segmento de la cordillera de los Andes que abarca la actual provincia de Neuquén, contiene una importante cantidad de pasos y/o portezuelos montañosos que permiten conectar y transitar ambas márgenes andinas con relativa facilidad. Tomando como referencia la cartografía oficial (Tognonato 1996), existe un total de 36 pasos montañosos en el sector norte que hemos delimitado que comprende desde el valle de la cuenca del Río Reñileuvu hasta el extremo noroeste de la provincia de Neuquén (en su límite con la provincia de Mendoza), y el sureste de la región del Maule, Chile (Figura 1).

En cuanto al ambiente (Figura 2), en la región el clima es cálido y seco en verano, llegando a los $40^{\circ}$ $\mathrm{C}$, y subtemplado en invierno, con mínimas de $-13^{\circ} \mathrm{C}$. Una característica importante es que la Cordillera del Viento contribuye a acentuar las condiciones de aridez al oriente, ya que actúa de barrera a los vientos húmedos que logran cruzar la cordillera de los Andes desde el Pacífico. Estas características determinan la marcada estacionalidad observada en el norte neuquino, siendo la vegetación correspondiente a la ecorregión de la estepa patagónica (Burkart et al. 1999).

\section{Antecedentes}

\section{Investigaciones rupestres del norte de Neuquén}

Desde sus inicios, los estudios rupestres del norte de Neuquén se concentraron principalmente en la Cuenca alta del Río Neuquén y en algunos tramos del Río Barrancas (Fernández 2000 [1979]; Schobinger 1956). Estas primeras investigaciones tuvieron como objetivo principal la construcción de tipologías, con el fin de discutir su pertenencia a los estilos de arte rupestre patagónicos (Menghin 1956). En este marco, se estableció para el norte de Neuquén el "estilo de paralelas" como un estilo sui generis diferenciado del resto de los estilos patagónicos, aunque circunscrito espacialmente a la cuenca alta del Río Neuquén (Fernández 2000 [1979]). Este autor postuló una cronología relativa para este estilo, ubicando sus comienzos en el siglo XIII DC. Durante la década de 1970, momento de auge de los estudios rupestres del norte neuquino, se lleva a cabo en la región del Maule (Chile) el relevamiento de importantes sitios con petroglifos, lo que daría como resultado la propuesta de un nuevo estilo denominado "guaiquivilo" (Niemeyer y Weisner 1972- 


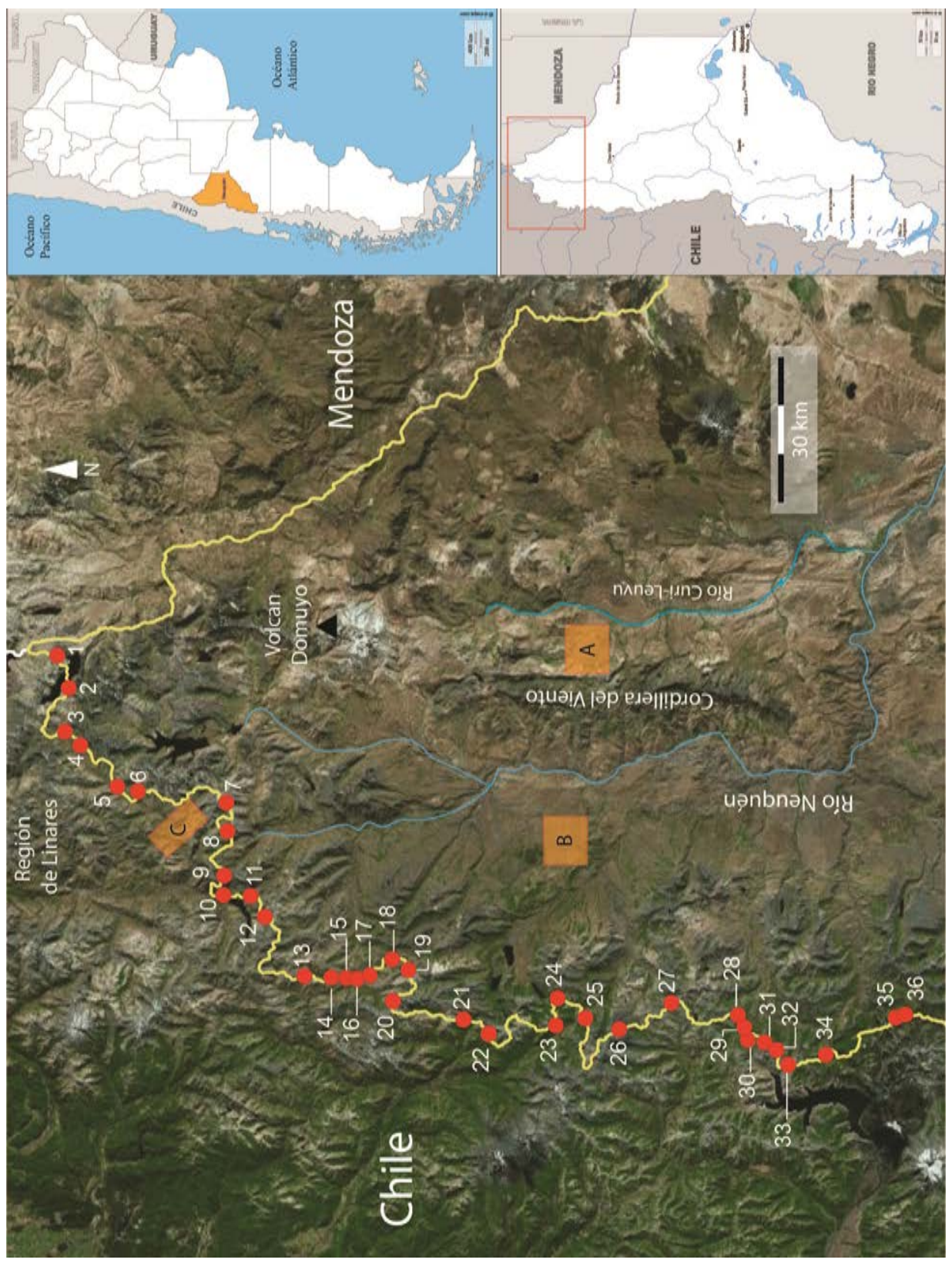

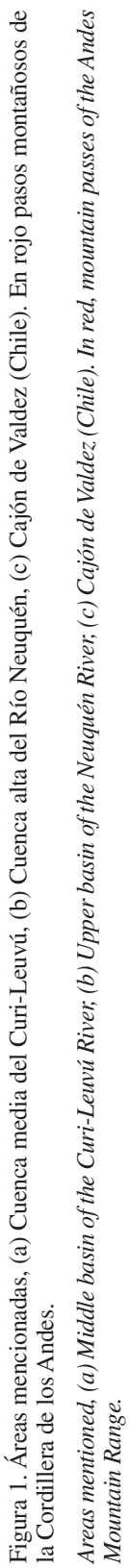




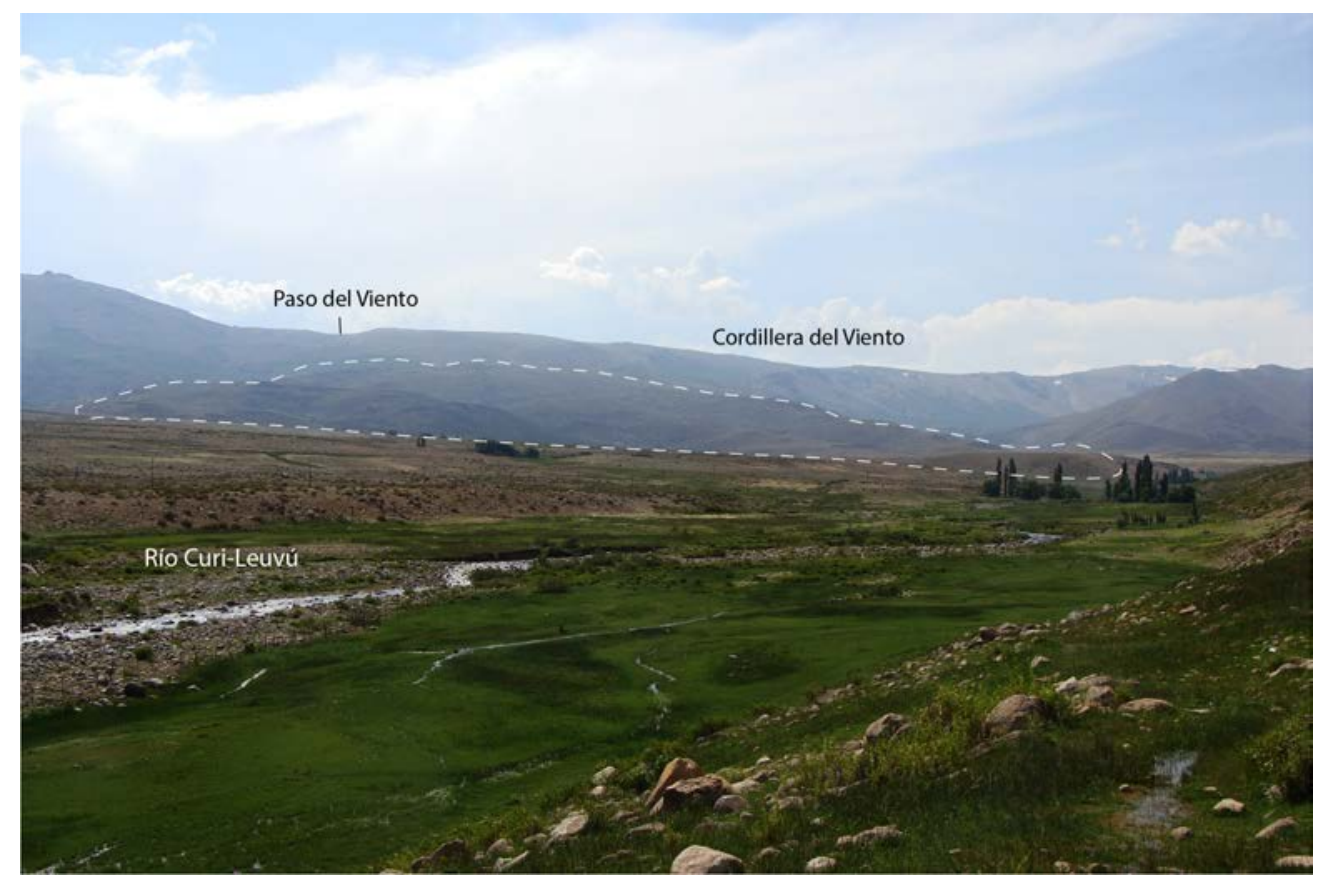

Figura 2. Paisaje de la Cuenca del Curi-Leuvú y faldeo este de la Cordillera del Viento. Línea segmentada delimita el sector donde se encuentran los bloques con grabados.

Landscape of the Curi-Leuvú Basin and east mountainside of the Cordillera del Viento. Dotted line delimits the sector where the slabs with engravings are located..

1973). Estos autores, también efectuaron apreciaciones cronológicas, ubicando este estilo entre los siglos XII y XVI DC. En este contexto, la contemporaneidad de las investigaciones en ambas vertientes cordilleranas permitió un corto pero intenso debate acerca de los vínculos estilísticos transcordilleranos y sus respectivas cronologías (Cuneo 2017; Vargas 2015).

Luego de unos 20 años, las investigaciones rupestres en el norte de Neuquén retoman su impulso, principalmente en el marco de trabajos de síntesis para la puesta en valor de los sitios rupestres (Vega 1996). En la actualidad, los proyectos arqueológicos de índole micro y macro regional en la región han integrado definitivamente los estudios rupestres como una línea de evidencia más dentro de los modelos de uso del espacio (Barberena 2013; Barberena et al. 2017; Hajduk y Cuneo 2009; Romero y Re 2014; Vargas 2015). No obstante, trabajos recientes han retomado las discusiones respecto de la extensión y configuración de los diferentes estilos presentes en la cuenca alta del rio Neuquén (Cuneo 2017). En el caso de la región del Maule, la discontinuidad en las investigaciones rupestres se evidencia en los escasos antecedentes citados. Sin embargo, recientemente se han efectuado algunos avances, en cuanto a la puesta al día de la historia de las investigaciones en la región, la prospección de nuevos sitios y propuestas para su activación patrimonial (Morales Yamal et al. 2017). Por otra parte, Blanco et al. (2015), en un trabajo comparativo, han retomado la discusión respecto a los posibles orígenes y vínculos del mencionado "estilo guaiquivilo" con estilos definidos para el centro-sur de Chile (Mostny y Niemeyer 1983; Niemeyer y Montané 1966).

Particularmente, dentro de la cuenca del CuriLeuvú, las investigaciones sobre arte rupestre han sido preliminares, abordando de forma sintética la diversidad de sitios, su emplazamiento en el paisaje y sus posibles relaciones con estilos previamente definidos para la región (Hajduk y Cuneo 2009). No obstante, se cuenta con un fechado absoluto por termoluminiscencia sobre fragmentos cerámicos hallados en capa y asociados a un fragmento descascarado de un petroglifo, lo que permite asignar una edad relativa de $925 \pm 95$ años AP (UCTL 2029) y 1090 \pm 110 años AP (UCTL 2030) (año base 2010) (Cuneo 2017; Hajduk et al. 2011b). Este fechado es coherente con la cronología del Holoceno Tardío planteada para los grabados rupestres de la cuenca alta del Río Neuquén (Fernández 2000 [1979]) y el cajon de Valdez (Niemeyer y Weisner 1972-1973).

\section{Imágenes Rupestres y Modelos Arqueológicos del Norte de Neuquén}

Aunque la información arqueológica disponible para la cuenca del Curi-Leuvú es diversa, abundante y proviene de contextos arqueológicos diferentes (ver 
compilación de Gordon et al. 2017; Hajduk et al. 2007), se ha postulado un modelo preliminar sobre el uso del espacio. En este sentido, Hajduk y Lezcano (2007), tomando como referencia el sistema actual de trashumancia y resaltando la importancia de la marcada estacionalidad del norte de Neuquén, postulan que el modo de vida en el pasado se articulooó entre "veranadas" ubicadas en espacios por encima de los $2.000 \mathrm{msm}$, e "invernadas" en espacios entre y por debajo de los 1.000 y $1.500 \mathrm{msm}$. Bajo este marco de trabajo identificaron un total de 41 sitios arqueológicos distribuidos en toda la Cuenca del Curi-Leuvú (Hajduk y Lezcano 2007). Estos primeros datos permitieron corroborar, desde un punto de vista biogeográfico, que los factores altitudinales y ecológicos orientaron un uso diferencial del espacio en la cuenca debido a su accesibilidad estacional y, por consiguiente, determinaron también un aprovisionamiento diferencial de los recursos (Hajduk y Lezcano 2007:405). Las evidencias rupestres de la Cuenca del Curi-Leuvú exhiben también, en parte, una estructuración en función de estas variables geográficas y ambientales (Hajduk y Cuneo 2009), donde los sitios con grabados se circunscriben a la cuenca media-alta, y los sitios con pinturas se encuentran en los tramos bajos de la cuenca (Figura 3).

A una escala regional, retomando en parte algunas hipótesis de Hajduk y Lezcano (2007), Barberena (2013) postula también un modelo de base biogeográfico para todo el norte de Neuquén, estableciendo una jerarquía de espacios y determinadas expectativas arqueológicas en función de su accesibilidad (estacional o anual) y su capacidad de carga $\mathrm{K}^{1}$. Complementariamente, los estudios llevados a cabo en el norte neuquino sobre geoquímica de obsidianas nos brindan información relevante sobre la movilidad y rangos de acción a partir del uso regional de diferentes tipos químicos que se encuentran disponibles en los distintos pisos altitudinales (Barberena et al. 2019; Fernández et al. 2017). La presencia del tipo químico Laguna del Maule 1-Laguna Negra (ca. 2.400 $\mathrm{msm}$ ), de disponibilidad estacional, en espacios bajos como las localidades Barrancas-Buta Ranquil, demuestra algún tipo de interacción con espacios altos durante el Holoceno Tardío (Fernández et al. 2017).

En relación a la evidencia rupestre, según Barberena (2013), la expectativa es que en espacios con alta

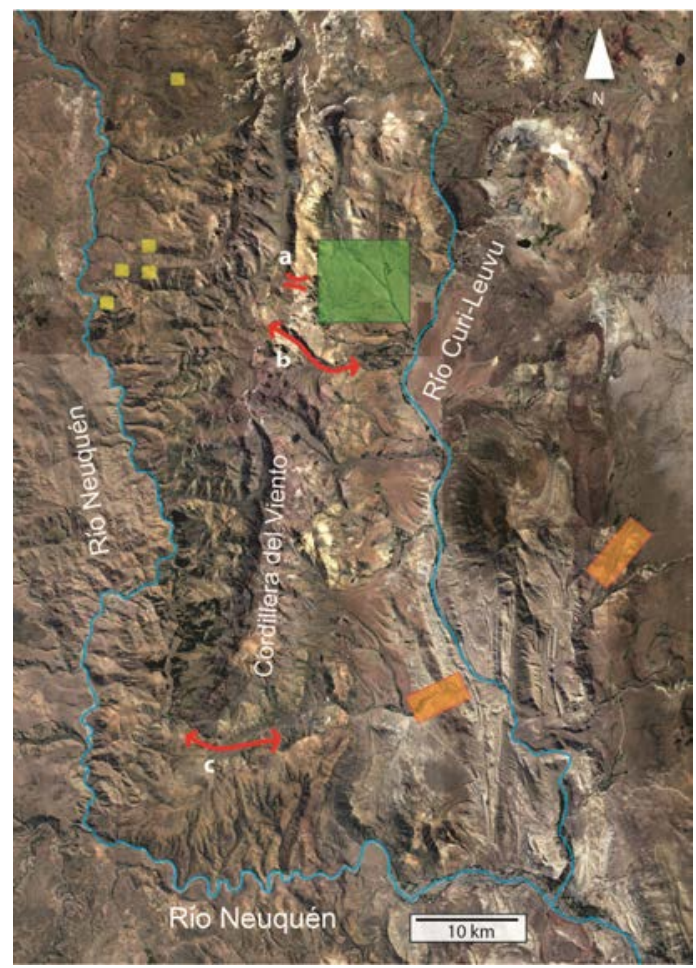

Figura 3. Sitios rupestres en la cuenca del Curi-Leuvu. En verde localidad Molulco-Mogotillos con grabados, en naranja los sitios con pinturas. En amarillo algunos sitios rupestres de la cuenca Neuquina. En rojo tres pasos montañosos, (a) Paso de Viento, (b) Tocuyo y (c) Cudio.

Rock art sites in the Curi-Leuvú Basin. In green, the locality of MolulcoMogotillos with engravings; in orange, the sites with paintings. In yellow, some rock art sites of the Neuquén basin. In red, three mountain passes, (a) Paso de Viento, (b) Tocuyo and (c) Cudio. 
K se constate mayor diversidad y densidad de motivos producto de procesos de competencia, lo que habría redundado en una intensa demarcación simbólica del territorio por medio del arte rupestre. Basándose en este modelo, Romero y $\operatorname{Re}(2014)$ plantean que, si bien macro regionalmente el norte neuquino compartió una dinámica en la circulación de información a través del arte rupestre, es posible postular también la existencia de una jerarquización de espacios en función de la diversidad y densidad de motivos presentes. En la misma línea, recientemente Barberena et al. (2017) amplían y precisan estas expectativas, postulando que a una escala regional, en los espacios altos y estrictamente estacionales del norte Neuquino (por encima de los $2.000 \mathrm{msm}$ ), es esperable constatar mayor diversidad de motivos, aunque no necesariamente una mayor densidad, como vía para comprobar la existencia de distintas pautas y/o escenarios de interacción social en la región.

Dentro del contexto regional, Barberena (2013) postula que la Cuenca del Curi-Leuvú habría sido de alto riesgo para las poblaciones humanas, debido a su baja conectividad topográfica y acceso estacional restringido; sin embargo, se trata a su vez de un ambiente que posee estacional y anualmente una elevada capacidad K (Barberena 2013). Así, según el modelo mencionado, ya en instancias de ocupación humana efectiva del espacio (Holoceno Tardío), la Cuenca del Curi-Leuvú habría favorecido procesos de competencia y, por consiguiente, una intensa ocupación y marcación del espacio por medio del arte rupestre. En este marco, Romero y Re (2014) postulan que las inferencias del modelo biogeográfico en la Cuenca del Curi-Leuvú podrían verificarse positivamente a partir del análisis comparativo de la distribución y densidad de sitios y diseños rupestres.

\section{Imágenes Rupestres, Información y Espacialidad}

En la actualidad los estudios rupestres patagónicos se han integrado como evidencia relevante dentro de las problemáticas arqueológicas planteadas a escala regional, de forma tal que permiten corroborar y/o complementar las hipótesis referidas a modelos de poblamiento, construcción de paisajes y usos del espacio o ambientes a través del tiempo (Acevedo et al. 2014; Belardi 2006; Boschin 2009; Carden 2008; Crivelli 2006; Charlin y Borrero 2012; Fiore 2006; Fiore y Acevedo 2018; Podestá et al. 2008; Re y Guichon 2009; Scheinsohn 2011; entre otros). En este contexto, las imágenes rupestres constituyen la evidencia de probables estrategias sociales y/o identitarias de marcación visual o territorial del espacio, sea como producto de procesos de competencia, mecanismos de interacción social, redes sociales o de información (Barberena 2013;
Domingo et al. 2008; Gallardo et al. 2012; McDonald y Veth 2012; Troncoso et al. 2016; entre otros)

En este marco, estas manifestaciones materiales $\mathrm{y}$ al mismo tiempo visuales, constituyen un indicador arqueológico más, que si bien formó parte de la esfera ideológica y/o cosmovisional de las sociedades indígenas, entrega información relevante respecto de las dimensiones cognitivas, económicas y sociales de las sociedades que la produjeron. En este sentido, la producción de imágenes rupestres reviste un carácter complejo y multidimensional (sensu Fiore 2009), con capacidad de agencia, al formar parte central en la mediación de procesos sociales (Fiore 2011).

En consecuencia, todo acto de producción materialvisual produce y reproduce no solo la dimensión tecnológica y representativa, sino también la dimension valorativa, estética, cognitiva y de información que se despliegan en la vida de una sociedad / grupo humano. Este último aspecto es de central importancia, ya que durante y después de la producción visual es cuando se consuman las instancias de adquisición, producción, circulación y transmisión de información (sensu Whallon 2011). No obstante, es importante remarcar que Whallon (2011) plantea un concepto amplio de información, que lo vincula directamente a la esfera del conocimiento, que incluye el saber cómo hacer las cosas (sentido práctico), como también pautas y/o prescripciones sociales sobre la conducta, el conocimiento del ambiente, sus condiciones y disponibilidad de recursos.

Con este marco, es posible caracterizar y corroborar la capacidad y potencialidad de las imágenes rupestres de transmitir información a partir del grado de estandarización de los diseños, ya que esa es una condición necesaria para su codificación y decodificación visual (Fiore 2011). La estandarización implica la repetición y/o recurrencia de la esfera tecnológica (específicamente las técnicas y conocimientos usados en el proceso de trabajo) y representativas (visuales) en la producción rupestre, sobre la cual operó un determinado grado de control social (Acevedo et al. 2014; Fiore 2007, 2009). De este modo, constatar la recurrencia en la reproducción y replicación de los elementos técnicos y representativos a diferentes escalas espaciales, nos permite inferir en qué medida se controló el proceso productivo, y como consecuencia, las instancias de transmisión de información antes mencionadas en los diferentes momentos de ejecución.

En suma, toda producción de imágenes rupestres configura prácticas potencialmente significativas $\mathrm{y}$, a su vez, comunicativas que contribuyen a conceptualizar, organizar y configurar la experiencia social por medio de la fijación de las imágenes y sus múltiples significados en distintos espacios. En este sentido, consideramos pertinente evaluar en esta primera instancia de trabajo la presencia de códigos visuales estandarizados y su 
distribución en el espacio, de forma tal que nos permita corroborar y contrastar las hipótesis de los modelos arqueológicos sobre uso, acceso y jerarquización del espacio en el norte de Neuquén. En relacion a esto último, por jerarquía espacial, hacemos referencia a espacios que presentan mayores evidencas de intensidad ocupacional estén o no asociados a nodos ocupacionales (sensu Barberena 2008).

\section{Hipótesis de Trabajo}

Considerando los modelos arqueológicos de base biogeográfica mencionados, planteamos que la marcada estacionalidad del Norte Neuquino, particularmente en la cuenca media del Curi-Leuvú donde se localizan los grabados rupestres, tuvo como correlato diferencias respecto de las actividades desarrolladas por los grupos cazadores-recolectores en distintos espacios. Específicamente, a escala de la cuenca media del Curi-Leuvú, nos interesa explorar la existencia de una posible jerarquización espacial a partir de las diferencias expresadas en términos de diversidad y densidad de motivos grabados emplazados a distintas cotas y escalas. Es necesario aclarar que en esta instancia todos los sitios rupestres se consideran, a priori, como sincrónicos debido a que hasta la fecha no contamos con cronologías absolutas de los grabados rupestres del Curi-Leuvú.

Proponemos que en ambos espacios (altos y bajos), la producción rupestre se estructuró de formas disímiles, donde la variabilidad expresada en términos de motivos implicó una producción y circulación de códigos visuales e información diferentes. Como consecuencia, en la cuenca del Curi-Leuvú existiría una relación entre espacios y tipos de motivos. A escalaregional planteamos que, si bien toda la cuenca del Curi-Leuvú pudo haber actuado como nodo ambiental atractivo, aunque de alto riesgo para las poblaciones (sensu Barberena 2013), es esperable constatar comparativamente mayor diversidad de códigos visuales. A su vez, cconsideramos que las similitudes observadas en términos de tipos de motivos compartidos en ambas vertientes de la Cordillera del Viento y de los Andes, abonarían la hipótesis de una elevada conectividad y uso estacional de los espacios altos (Barberena et al. 2017), y por consiguiente una intensa producción y circulación de códigos visuales e información.

\section{Materiales y Métodos}

Para el presente trabajo el muestreo se basó en las variables altitudinales con el fin de identificar grabados a distintas cotas, así como también en las características geológicas del área y la disponibilidad de rocas soporte susceptibles de ser grabadas, identificadas previamente (Vargas 2015). De este modo, se tomaron como muestra los sitios con grabados relevados en las campañas 2014 y 2015 (Vargas 2015). La estrategia metodológica en ese entonces se orientó a profundizar los relevamientos previos en la confluencia de los arroyos Molulco y Mogotillos (Hajduk y Cuneo 2009), sobre el faldeo este de la Cordillera del Viento (Figura 3).

En este trabajo, no se incorporan para el análisis los datos de los sitios con pinturas del Curi-Leuvú, debido a que hasta la fecha no contamos con relevamientos sistemáticos efectuados sobre estos sitios. No obstante, partimos de la premisa metodológica de que las técnicas de pintura y de grabado implicaron procesos y decisiones tecnológicas considerablemente diferentes (Fiore 2007) como consecuencia, que estos dos registros posiblemente refieran a contextos de producción y uso diversos. En este sentido, estimamos que las distintas técnicas estuvieron mediadas por dimensiones cognitivas, económicas y sociales que implican procesos de enseñanza y aprendizaje dferentes (Fiore 2006). Es por esta razón, que la dimensión tecnológica involucra, y a la vez permite evaluar y diferenciar, procesos identitarios, sociales o productivos de larga duración (Domingo et al. 2008).

Las pinturas rupestres se localizan en la cuenca baja del Río Curi-Leuvú, a unos 35 km en línea recta hacia el sur de la concentración de grabados de la confluencia del Molulco-Mogotillos. A su vez, estos sitios se emplazan en contextos espaciales considerablemente diferentes, ya que las pinturas se hallan en cuevas o aleros de difícil acceso (que se presentan una muy baja visibilidad), mientras que los grabados se extienden sobre amplias superficies en el faldeo Este de la Cordillera del Viento.

Para el análisis formal de los grabados, se priorizó la identificación de las unidades visuales mínimas (motivos), las características generales de las técnicas empleadas, la cantidad de caras del soporte y los paneles efectivamente intervenidos. De forma cualitativa, se consideró el efecto figura-fondo producto de la extracción de la pátina de los soportes. La clasificación de los motivos, tanto a nivel de tipos como de grupos, se elaboró a partir de los lineamientos propuestos principalmente por Niemeyer y Wiessner (1972-1973) y Fernández (2000 [1979]2). Incluimos las categorías de figurativo y no figurativo para la distinción entre diseños con un referente real conocido de los que no lo tienen (sensu Fiore 2011).

En cuanto al análisis comparativo a escala regional, se incorporaron los datos de los sitios mencionados también por Fernández (2000 [1979]) y Cuneo (2017) para la Cuenca Neuquina. Para la región del Maule, se incluyeron en esta instancia solamente los sitios del Cajón de Valdez, ubicado al este de la localidad de Linares, trabajados por Niemeyer y Weisner (1972-1973), 
debido a su proximidad geográfica con el paso Valdez, que conecta ambas vertientes de la cordillera de los Andes (Figura 1). El análisis contextual-espacial se basó en la delimitación de espacios altos, intermedios y bajos establecida por Barberena et al. (2017). Para identificar posibles diferencias entre motivos y su distribución en el espacio, tanto a escala de la cuenca del Curi-Leuvú como a escala regional, se efectuaron análisis de rarefacción ${ }^{3}$ para estimar la riqueza o abundancia relativa de los tipos y grupos de motivos presentes. A escala regional se aplicaron también índices de diversidad, para conocer como se distribuyen las frecuencias de los motivos al interior de los grupos (la heterogeneidad o dominancia en cada caso). Complementariamente elaboramos tablas de contingencia a fin de realizar análisis de chi que permitiesen testear la posible relación entre tipos de motivos y tipos de espacios en la cuenca del Curi-Leuvú.

Estos análisis nos permitieron establecer algunas proyecciones estadísticas predictivas para generar escenarios posibles de contrastar o testear a medida que los diferentes investigadores del área avancen en los estudios rupestres ${ }^{4}$. Finalmente, ponderamos el conjunto de sitios a partir de su distribución espacial, considerando principalmente su localización topográfica y vinculación con pasos cordilleranos.

\section{Resultados}

\section{Análisis a escala de la Cuenca Curi-Leuvú}

En la Cuenca del Curi-Leuvú, en el área donde confluyen los arroyos Molulco y Mogotillos, se prospectó un total de $18 \mathrm{~km}^{2}$ y se relevaron 37 bloques rupestres con un total de 355 motivos grabados identificados (Figura 4). En cuanto al tipo de soporte, todas las rocas seleccionadas para la confección de los grabados fueron las andesitas que están presentes en la formación Cordillera del Viento (Guerello 2006). Este tipo de roca se encuentra distribuida, en forma de rodados de tamaño variable, como un continuum sobre el faldeo este de la Cordillera del Viento y la confluencia de los arrollos Molulco y Mogotillo, producto de los distintos procesos geomorfológicos acontecidos en el pasado (González y Folguera 2011). De este modo, resulta casi imposible estimar diferencias en la abundancia respecto a una eventual disponibilidad de soportes, debido a que los bloques se presentan en grandes cantidades sobre los espacios delimitados.

Una de las características más destacables de estas rocas soportes es que poseen muy buenas cualidades para el grabado debido a su relativa baja dureza y el efecto que se obtiene al momento de extracción de

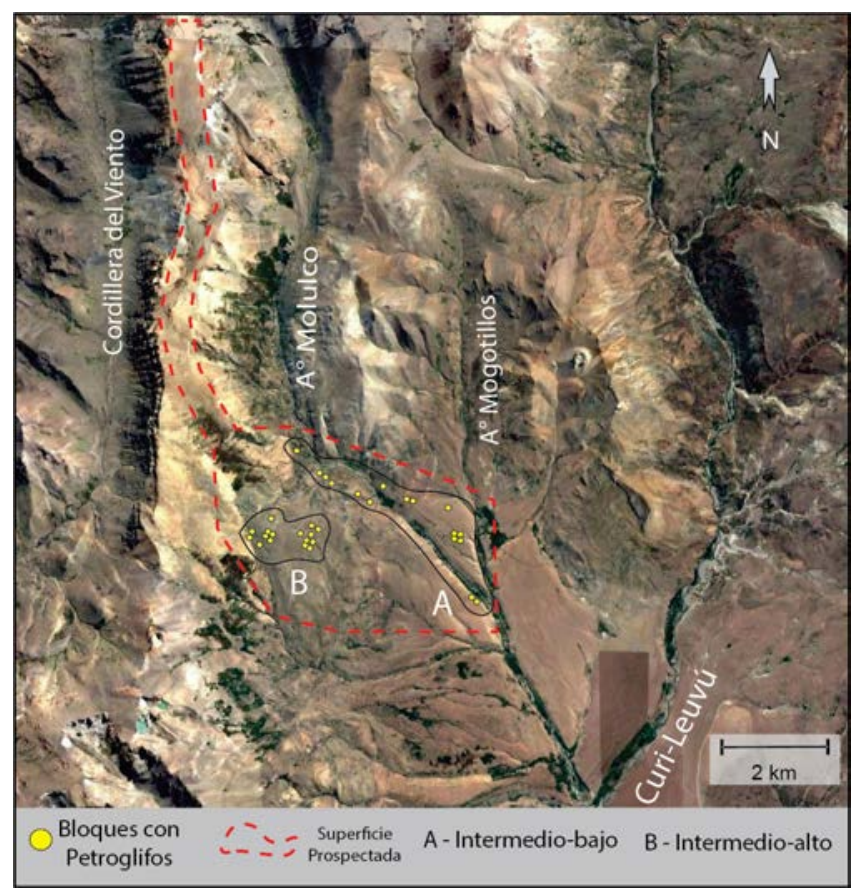

Figura 4. Mapa área rupestre (Ao) Molulco-Mogotillos. Concentraciones en espacios altos y bajos.

Map of the rock art town (Ao) Molulco-Mogotillos. Concentrations in high and low spaces. 
la pátina lo que genera una diferencia con la tonalidad clara del surco grabado. Para la elaboración de los motivos en todos los bloques fue utilizada la técnica del piqueteo, con una profundidad del surco también similar de máximo unos dos mm (Vargas 2015).

En cuanto a los motivos, pudimos identificar un total de 56 tipos, de los cuales solo seis corresponden a los motivos figurativos y el resto a motivos nofigurativos (Tabla 1, Figuras 5-6-7-8). A su vez, estos tipos fueron agrupados en 21 grupos de motivos (Tabla 2, Figura 9)

En términos espaciales, y en función de los parámetros altitudinales, identificamos dos

Tabla 1. Frecuencia de tipos de motivos.

\begin{tabular}{ccc}
\multicolumn{3}{c}{ Frequency of types of motifs. } \\
\hline & $\begin{array}{c}\mathrm{N}^{\circ} \text { Tipos de } \\
\text { motivos }\end{array}$ & $\begin{array}{c}\mathrm{N}^{\circ} \text { Total } \\
\text { motivos }\end{array}$ \\
\hline Motivos Figurativos & 6 & 51 \\
Motivos no figurativos & 50 & 304 \\
Total & 56 & 355 \\
\hline
\end{tabular}

concentraciones de la distribución de los soportes grabados (Tabla 3, Figura 4). Por un lado, en la concentración $\mathrm{A}$, los bloques erráticos se emplazan en el espacio intermedio-bajo y se distribuyen sobre ambas márgenes del arroyo Molulco. En la concentración $\mathrm{B}$, los bloques se circunscriben al espacio intermedio-alto, sobre el faldeo este de la cordillera del Viento y por encima de las pequeñas terrazas que contienen la concentración de bloques erráticos. Así mismo, aún teniendo en cuenta que la disponibilidad de materia prima en ambos espacios es relativamente similar en términos de abundancia, es posible observar diferencias en relación a la intensidad de grabado. De esta manera, en comparación con la concentración A, en la concentración B si bien hay más motivos en total, hay también más paneles intervenidos respecto del total de soportes. No obstante, si bien las dos concentraciones poseen proporciones diferentes en cuanto al número de caras susceptibles de ser grabadas respecto de la cantidad de bloques, la concentración B posee más caras aprovechadas respecto de la concentración A (Tabla 2).

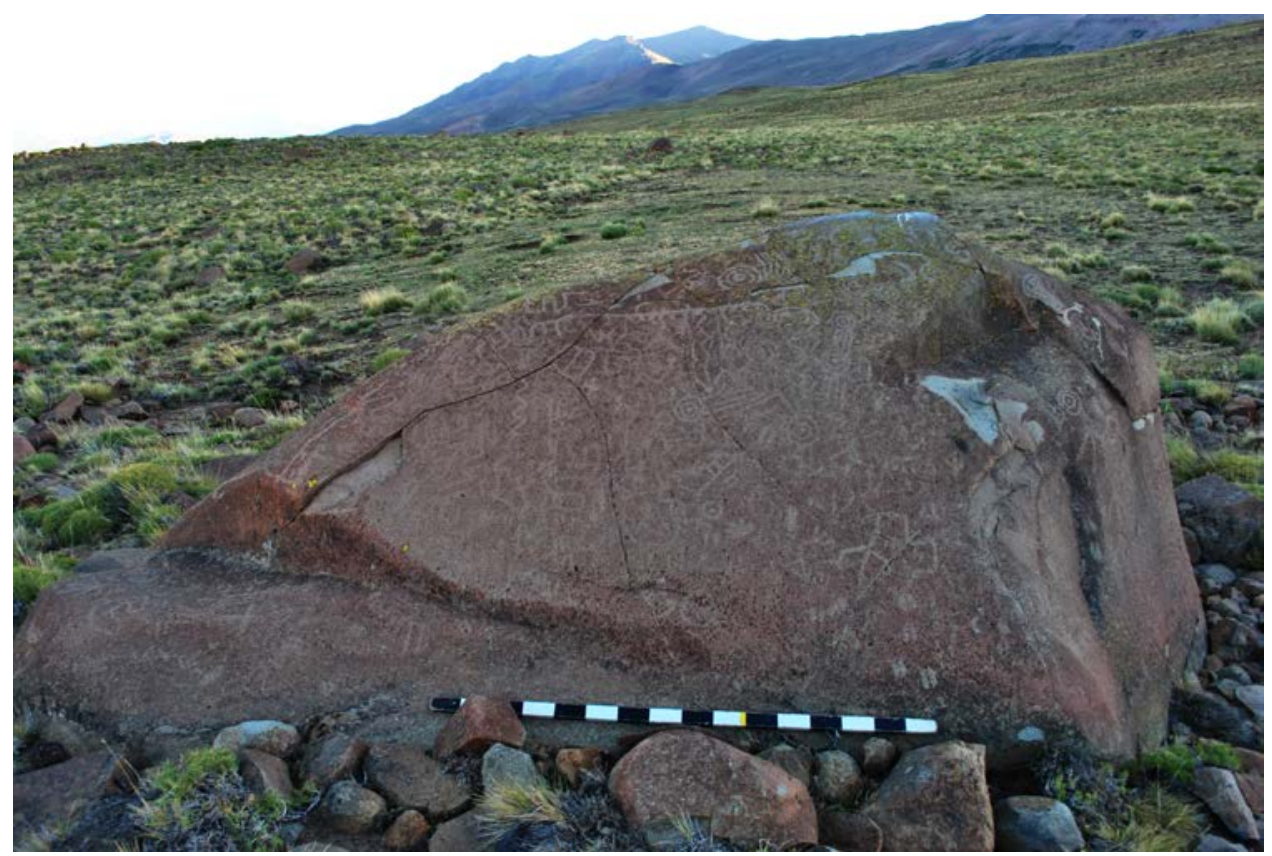

Figura 5. Bloque emplazado en el espacio alto con sus caras norte y oeste profusamente grabadas.

Block located in the high space with its north and west faces profusely engraved. 


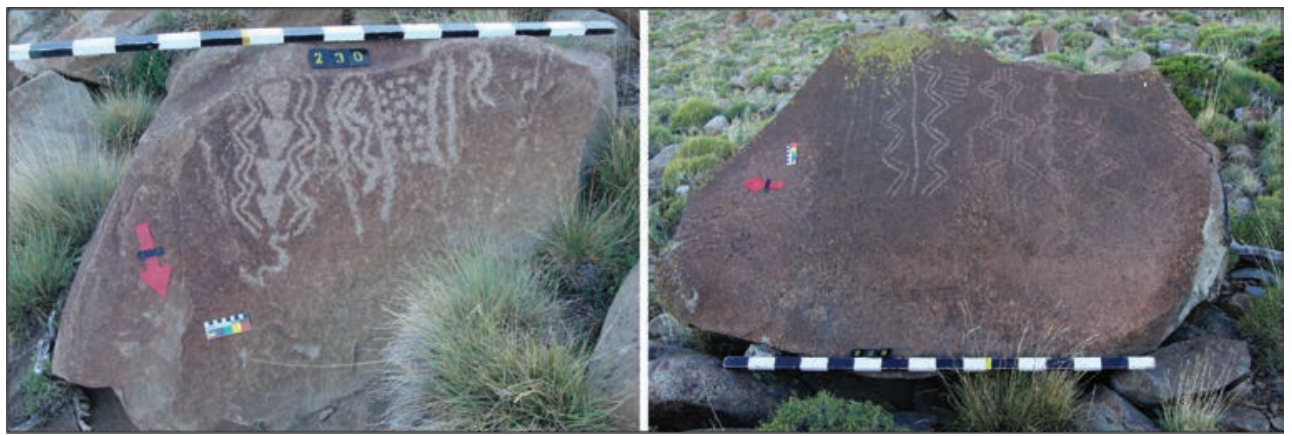

Figura 6. Bloques emplazados en espacios altos con motivos que son también recurrentes en la cuenca Neuquina. Blocks located in high spaces with motifs that are also recurrent in the Neuquén basin.

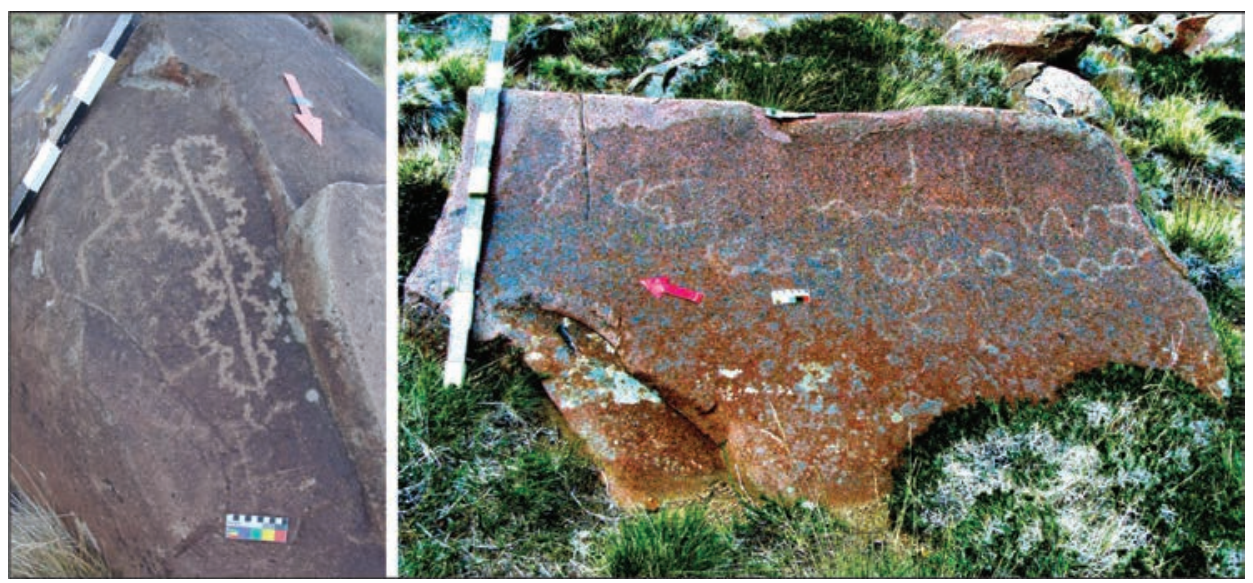

Figura 7. Bloques en espacios altos. Variabilidad de motivos de simetría axial a la izquierda y a la derecha motivos circulares con apéndices.

Blocks in high spaces. Variability of motifs of axial symmetry to the left and to the right circular motifs with appendages.
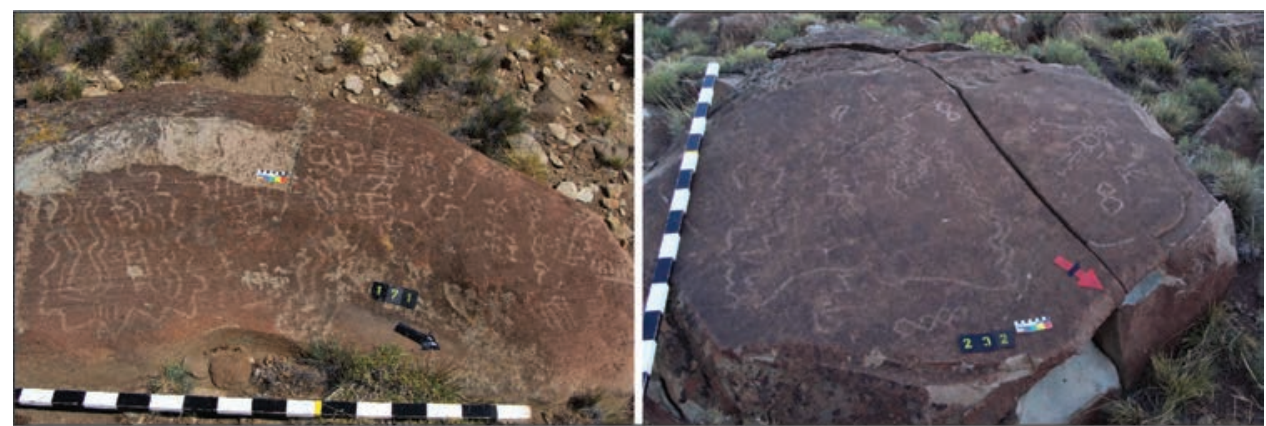

Figura 8. Bloque en el espacio bajo a la izquierda profusamente grabado y a la derecha bloque en el espacio alto. Block in the low space to the left profusely engraved and, to the right, slab in the high space. 
Tabla 2. Tabla con los grupos de motivos por cuenca.

Table with the groups of motifs by basin.

\begin{tabular}{|c|c|c|c|c|c|c|c|}
\hline & \multirow[t]{2}{*}{ Grupos de Motivos } & \multicolumn{2}{|c|}{ Cuenca Curí-Leuvú } & \multicolumn{2}{|c|}{ Cuenca Neuquén } & \multicolumn{2}{|c|}{ Cuenca Cajón de Valdez } \\
\hline & & $f$ & $\%$ & $f$ & $\%$ & $f$ & $\%$ \\
\hline 1 & Puntiformes y segmentiformes & 8 & 2,25 & 77 & 18,73 & 173 & 10,23 \\
\hline 2 & Líneas rectas y curvilíneas simples & 59 & 16,62 & 23 & 5,60 & 0 & 0,00 \\
\hline 3 & Paralelas & 49 & 13,80 & 110 & 26,76 & 131 & 7,75 \\
\hline 4 & Círculos & 76 & 21,41 & 42 & 10,22 & 97 & 5,74 \\
\hline 5 & Sucesión de triángulos & 10 & 2,82 & 8 & 1,95 & 3 & 0,18 \\
\hline 6 & Trazos rectos con segmentos transversales hacia un lado ("Rastrillo") & 9 & 2,54 & 12 & 2,92 & 4 & 0,24 \\
\hline 7 & $\begin{array}{l}\text { Trazos rectos con segmentos transversales cortos ("Escaleras de un } \\
\text { palo") }\end{array}$ & 10 & 2,82 & 17 & 4,14 & 15 & 0,89 \\
\hline 8 & Subcírculo de cuerpo lleno unidos por eje vertical ("Alfileres") & 2 & 0,56 & 7 & 1,70 & 5 & 0,30 \\
\hline 9 & Reticulados ("Retiformes") & 5 & 1,41 & 6 & 1,46 & 15 & 0,89 \\
\hline 10 & Figuras adosadas de trazos combinados ("Lineaturas caprichosas") & 31 & 8,73 & 29 & 7,06 & 137 & 8,10 \\
\hline 11 & Figuras de simetría axial y contorno ondulante & 20 & 5,63 & 31 & 7,54 & 47 & 2,78 \\
\hline 12 & Antropomorfos & 2 & 0,56 & 2 & 0,49 & 9 & 0,53 \\
\hline 13 & Zoomorfos & 1 & 0,28 & 0 & 0,00 & 4 & 0,24 \\
\hline 14 & Improntas de pie humano & 0 & 0,00 & 9 & 2,19 & 621 & 36,72 \\
\hline 15 & Improntas de mano humana & 3 & 0,85 & 3 & 0,73 & 16 & 0,95 \\
\hline 16 & Rastros de animales & 45 & 12,68 & 29 & 7,06 & 177 & 10,47 \\
\hline 17 & Trazos rectos con segmentos transversales extendidos ("Fitomorfos") & 3 & 0,85 & 4 & 0,97 & 18 & 1,06 \\
\hline 18 & Varios ("Misceláneas") & 16 & 4,51 & 0 & 0,00 & 166 & 9,82 \\
\hline 19 & Clepsidras & 2 & 0,56 & 0 & 0,00 & 0 & 0,00 \\
\hline 20 & Indeterminados & 4 & 1,13 & 0 & 0,00 & 53 & 3,13 \\
\hline \multirow[t]{2}{*}{21} & Figuras con pliegues o laberínticas & 0 & 0,00 & 2 & 0,49 & 0 & 0,00 \\
\hline & Total & 355 & 100 & 411 & 100 & 1691 & 100 \\
\hline
\end{tabular}

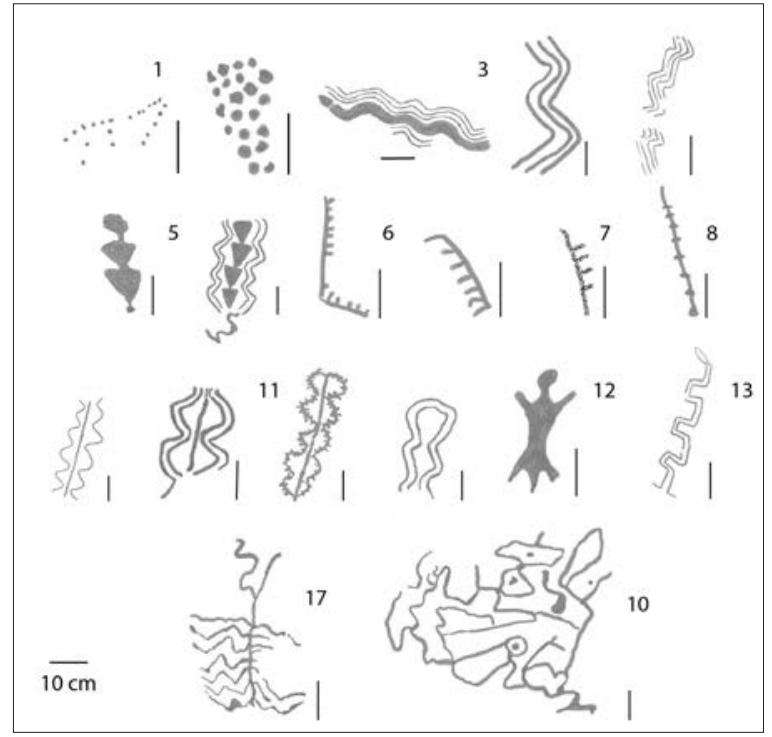

Figura 9. Tipos de motivos correspondientes a los grupos de motivos $\left(\mathrm{N}^{\circ}\right.$ correspondientes a la Tabla 5) más característicos.

Types of motifs corresponding to the most characteristic groups of motifs ( $N^{o}$ corresponding to Table 5). 
Tabla 3. Grabados en ambos espacios del Curi-Leuvú.

\begin{tabular}{cccccccccc}
\multicolumn{10}{c}{ Engravings in both spaces of the Curi-Leuvú. } \\
\hline \multirow{2}{*}{ Concentración } & Espacio & $\begin{array}{c}\mathrm{msm} \\
\text { promedio }\end{array}$ & $\begin{array}{c}\text { Bloques/ } \\
\text { Caras }\end{array}$ & Paneles & $\begin{array}{c}\mathrm{N}^{\circ} \text { Tipos motivos } \\
\text { Figurativos }\end{array}$ & $\begin{array}{c}\mathrm{N}^{\circ} \text { Tipos motivos } \\
\text { No-Figurativos }\end{array}$ & $\begin{array}{c}\text { Total } \\
\text { Tipos }\end{array}$ & $\begin{array}{c}\text { Total } \\
\text { Motivos }\end{array}$ \\
\hline A & Intermedio-bajo & 1.585 & $17(22)$ & 17 & 1 & 27 & 28 & 106 \\
\hline B & Intermedio-alto & 1.947 & $20(30)$ & 26 & 6 & 42 & 48 & 249 \\
\hline
\end{tabular}

Encontramos diferencias en términos de diversidad y densidad de los tipos de motivos presentes en ambos espacios. El gráfico de rarefacción (Figura 10) muestra que, aún considerando el tamaño de las muestras, existen diferencias significativas en la cantidad de tipos de motivos presentes de cada espacio. De este modo, en el espacio intermedio-bajo, para un total de 106 motivos identificamos 29 tipos de motivos mientras que, para ese mismo total de motivos; en el espacio intermedio-alto encontramos 35 tipos de motivos.

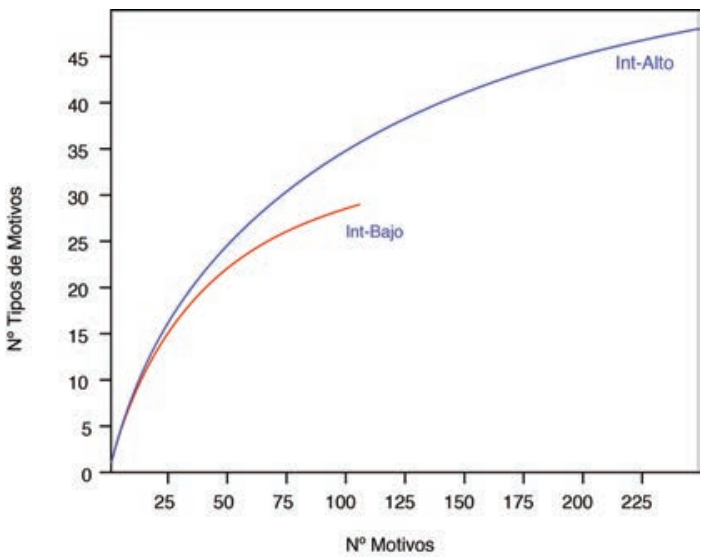

Figura 10. Gráfico de rarefacción comparativo de la Cuenca del Curi-Leuvú. Comparative rarefaction graph of the Curi-Leuvú Basin.

Complementariamente, efectuamos un análisis $\mathrm{chi}^{2}$ para testear la posible dependencia entre espacios y presencia - ausencia de tipos de motivos, (Tabla 4). Los resultados permiten sostener que existe una relación significativa entre espacios y motivos, debido a que la probabilidad de que la hipótesis nula sea cierta, es decir, que no haya relación entre espacios y motivos, es muy baja (con un valor $\mathrm{chi}^{2}$ 16,374; p. no assoc. 0,000051986). En suma, ambos análisis (rarefacción y chi ${ }^{2}$ ) sugieren que existe una relación clara entre la frecuencia de tipos de motivos y su ubicación espacial.

Tabla 4. Presencia y ausencia de motivos en ambos espacios.

\begin{tabular}{ccc} 
Presence and absence of motifs in both spaces. \\
\hline & Presencia & Ausencia \\
\hline intermedio-bajo & 29 & 28 \\
\hline intermedio-alto & 48 & 8 \\
\hline
\end{tabular}

En la misma línea, también buscamos identificar diferencias en función de la frecuencia de motivos figurativos y no figurativos en estos espacios (Tabla 5). Nuevamente, los resultados muestran una alta asociación entre espacios y grupos de motivos figurativos/no-figurativos, ya que la probabilidad de que la hipótesis nula sea cierta también es muy baja (valor chi² 22,133; p. no assoc. 0,0000025444). Esto sugiere también una dependencia espacial de la frecuencia de motivos figurativos y no figurativos.

Tabla 5. Frecuencia de motivos no figurativos y figurativos en ambos espacios.

Frequency of non-figurative and figurative motifs in both spaces.

\begin{tabular}{ccc}
\hline & $\begin{array}{c}\mathrm{N}^{\circ} \text { Motivos } \\
\text { Figurativos }\end{array}$ & $\begin{array}{c}\mathrm{N}^{\mathrm{O}} \text { Motivos No- } \\
\text { figurativos }\end{array}$ \\
\hline Intermedio-bajo & 1 & 105 \\
Intermedio-alto & 50 & 199 \\
\hline
\end{tabular}

\section{Análisis comparativo a escala regional}

Para realizar la comparación a escala regional, elaboramos una clasificación tomando los sitios de la Cuenca Neuquina, del Cajón de Valdez y también de la Cuenca del Curi-Leuvú, estableciendo un total de 21 grupos de motivos (Tabla 2). En este caso, el análisis de rarefacción muestra diferencias significativas (Figura 11). Así, la cuenca del Curi-Leuvú, aún siendo la muestra de menor tamaño con un total de 355 motivos, presenta mayor riqueza de grupos de motivos con un total de 19 grupos (Tabla 6).

Como consecuencia, podemos afirmar provisoriamente que la Cuenca del Curi-Leuvú resulta levemente más rica en términos de presencia de grupos de motivos respecto del Cajón de Valdez, que con una muestra significativamente superior de motivos posee casi la misma cantidad de grupos de motivos con un total de 18. Diferente es la situación para la cuenca alta neuquina, que aún incluyendo recientes relevamientos (Cuneo 2017) que elevan su frecuencia a 411 motivos, presenta respecto de CuriLeuvú dos grupos menos de motivos representados con un total de 17. En suma, las tendencias estadísticas nos indican que, incluso si aumentáramos la muestra de las tres localidades, es esperable que la cuenca del CuriLeuvú aumente su riqueza. 


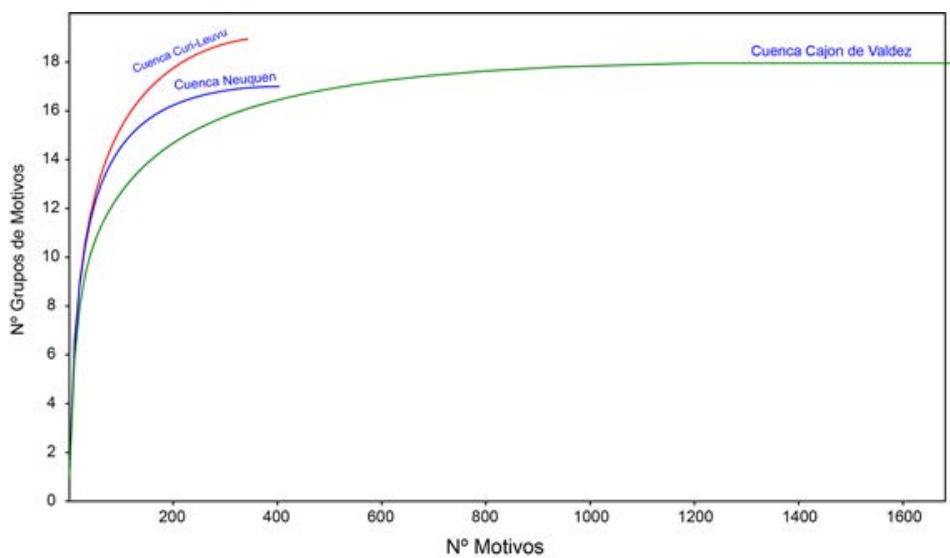

Figura 11. Gráfico de rarefacción comparativo a escala regional.

Comparative rarefaction graph at regional scale.

Tabla 6. Resultados del análisis de rarefacción e índices de diversidad Simpson y Shannon efectuados en Past3 (Hammer 1999-2018).

Results of the rarefaction analysis and Simpson and Shannon diversity indexes carried out in Past3 (Hammer 1999-2018).

\begin{tabular}{lccc}
\hline & $\begin{array}{c}\text { Cuenca } \\
\text { Curi-Leuvú }\end{array}$ & $\begin{array}{c}\text { Cuenca } \\
\text { Neuquén }\end{array}$ & $\begin{array}{c}\text { Cuenca } \\
\text { Cajón de } \\
\text { Valdez }\end{array}$ \\
\hline $\begin{array}{l}\text { Taxa_S ( } \mathrm{N}^{\circ} \text { Grupos de } \\
\text { motivos) }\end{array}$ & 19 & 17 & 18 \\
\hline $\begin{array}{l}\text { Individuals (No total } \\
\text { motivos) }\end{array}$ & 355 & 411 & 1691 \\
\hline $\begin{array}{l}\text { Dominance_D (1-Simp- } \\
\text { son index) }\end{array}$ & 0,1247 & 0,1401 & 0,1839 \\
\hline Shannon_H & 2,353 & 2,289 & 2,1 \\
\hline
\end{tabular}

En términos de diversidad, si bien existen leves diferencias en los resultados (Tabla 6), comparativamente la cuenca del Curi-Leuvú resulta levemente más diversa y, a su vez, presenta un menor valor en el índice de dominancia, contrariamente a lo que sucede en el cajón de Valdez, que presenta un valor cercano a 1. De este modo, donde más se expresan las diferencias, es en las frecuencias totales sobre los grupos de motivos que hemos agrupado como figurativos (Tabla 7), lo que explica las diferencias estadísticas antes mencionadas.

\section{Discusión}

Los resultados alcanzados en este primer trabajo nos permiten establecer provisoriamente que a escala de toda la Cuenca del Curi-Leuvú, si bien existen diferentes contextos espaciales de producción rupestre, tanto de pinturas como de grabados, la producción de estos últimos se estructura de formas significativamente disímiles en función de su emplazamiento en el espacio. En este sentido, los
Tabla 7. Frecuencia y porcentaje de los grupos de motivos figurativos en los tres espacios.

Frequency and percentage of groups of figurative motifs in the three spaces.

\begin{tabular}{lcccc}
\hline & $\begin{array}{c}\text { Cuenca } \\
\text { Curi- } \\
\text { Leuvú }\end{array}$ & $\begin{array}{c}\text { Cuenca Río } \\
\text { Neuquén }\end{array}$ & $\begin{array}{c}\text { Cuenca Cajón } \\
\text { de Valdez }\end{array}$ & Total \\
\hline Antropomorfos & 2 & 2 & 9 & 13 \\
\hline Zoomorfos & 1 & 0 & 4 & 5 \\
\hline $\begin{array}{l}\text { Improntas de } \\
\text { pie humano }\end{array}$ & 0 & 9 & 621 & 630 \\
\hline $\begin{array}{l}\text { Improntas de } \\
\text { mano humana }\end{array}$ & 3 & 3 & 16 & 22 \\
\hline $\begin{array}{l}\text { Rastros de } \\
\text { animales }\end{array}$ & 45 & 29 & 177 & 251 \\
\hline Total & 51 & 43 & 827 & 921 \\
\hline$\%$ & 5,5374 & 4,6688 & 89,7937 & 100 \\
\hline
\end{tabular}

resultados estadísticos muestran que el espacio intermedio-alto, presenta una mayor diversidad y cantidad de motivos respecto de los espacios bajos. Incluso, comparativamente, los soportes y paneles fueron más aprovechados en el espacio intermedioalto, aun cuando la disponibilidad de materias primas resulta similar tanto en abundancia como en términos de tipo y calidad para el grabado. Por otra parte, estas diferencias también se expresan cualitativamente en términos de la presencia de motivos figurativos y no figurativos. Así, el espacio intermedio-alto contiene la casi totalidad de motivos figurativos presentes en la muestra, a la vez que presenta una diferencia de 15 tipos de motivos no figurativos más que en el espacio intermedio-bajo (Tabla 2). Por consiguiente, estos datos nos permiten afirmar provisoriamente que hubo una producción y circulación diferencial de códigos visuales e información en ambos espacios. 
Ante estas diferencias nos preguntamos: $i$ a qué se debe la mayor variabilidad e intensidad de producción rupestre en los espacios intermedios-altos? Por un lado, sabemos que los espacios altos y estacionales del CuriLeuvú, funcionaron posiblemente como escenarios de caza (Hajduk y Lezcano 2007). A su vez, estos espacios cuentan con una amplia visibilidad de la cuenca (Vargas 2015), por lo que habrían permitido obtener buenos puntos de observación y control tanto de los recursos como de otros grupos (Figura 12). No obstante, si bien existen diferencias en cuanto a la disponibilidad de recursos entre los espacios altos y bajos $^{5}$, la configuración topográfica del faldeo este de la Cordillera del Viento, con pendientes suaves, sumada a los factores de atracción de los espacios altos (Barberena et al. 2017) los transforman en áreas favorables para el acceso, uso y circulación humana.

En este sentido, las diferencias observadas respecto de la producción y circulación de códigos visuales en los espacios altos posiblemente sea producto de la ocupación y tránsito estacional de diferentes grupos e individuos, dado su funcionamiento como espacios de convergencia poblacional y de uso compartido (sensu Barberena et al. 2017). Contrariamente, los espacios bajos cercanos a los cursos de agua permanentes, a priori, estarían más vinculados a un uso doméstico ${ }^{6}$. En suma, es posible afirmar que en ambos espacios del Curi-Leuvú hayan operado no solo diferentes estrategias de acceso y uso del espacio, sino también estrategias de control social de la producción rupestre, mediadas por prácticas sociales y comunicativas disímiles, de modo tal que circularon recursos e información con fines potencialmente diferentes.

A una escala regional, si bien observamos que en términos de riqueza y diversidad de grupos de motivos las diferencias no resultan muy significativas (Tabla 6), debemos volver a remarcar que las muestras analizadas poseen tamaños sensiblemente diferentes ${ }^{7}$. Si incluyéramos los registros de sitios con pinturas presentes en la Cuenca Neuquina y Curi-Leuvú, también aumentaría probablemente la diversidad y cantidad de motivos en cada uno de estos espacios. En cambio, no sucedería lo mismo con la región del Barrancas y Cajón de Valdez, donde el primero no posee sitios con grabados (Romero y Re 2014) y el segundo no presenta sitios con pinturas (Niemeyer y Weisner 1972-1973).

No obstante, en los registros comparados las diferencias se expresan en el modo en que las frecuencias de los motivos se distribuyen en los grupos de motivos. En este sentido, el Cajón de Valdez, posee una alta dominancia, lo cual indica una menor diversidad, debido a que posee un grupo de motivos que está mayormente representado. Este es el caso de las improntas de pie humano que representan el 32,76\% de la muestra.

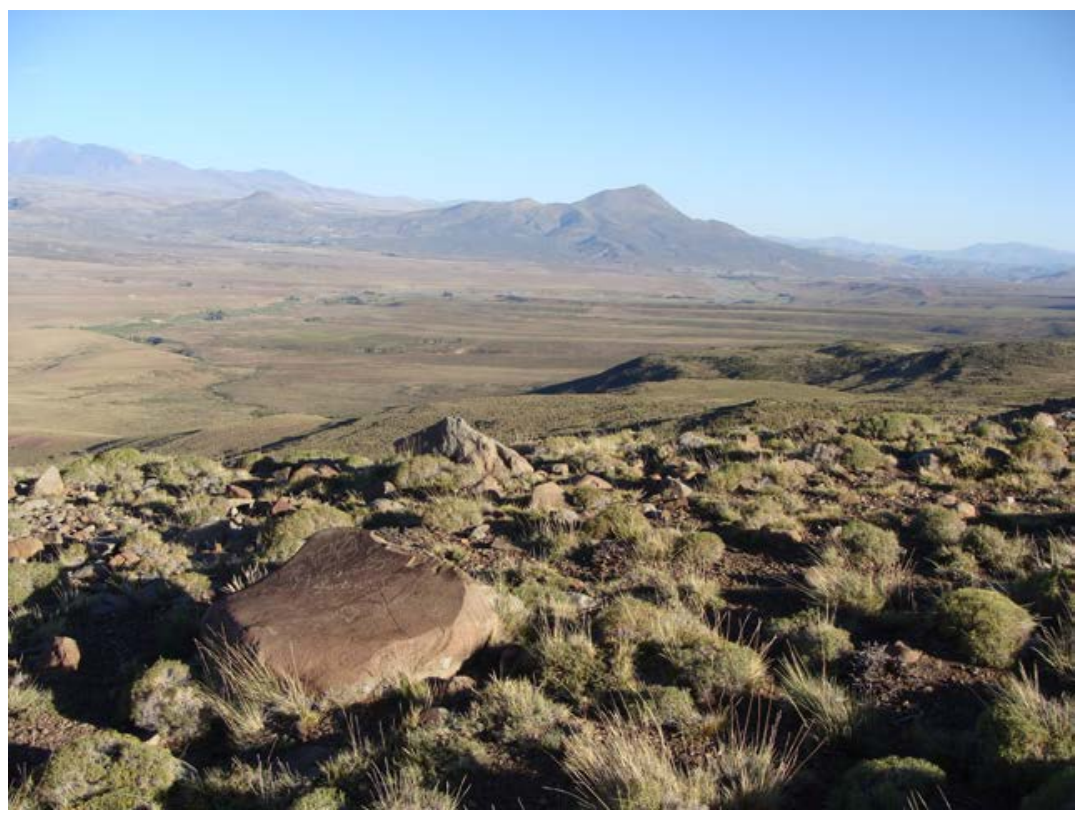

Figura 12. Vista desde el campo de petroglifos en la Cordillera del Viento hacia la Cuenca del Curi-Leuvú. $\mathrm{Al}$ fondo se visualiza el Cerro Negro $(2.500 \mathrm{msm})$ y Tromen $(4.144 \mathrm{msm})$

View from the field of petroglyphs in the Cordillera del Viento towards the Curi-Leuvu Basin. In the background the Cerro Negro (2,500 masl) and Tromen (4,144 masl). 
Haciendo referencia específica a la frecuencia de motivos figurativos de cada cuenca, es necesario mencionar que existen diferencias significativas en términos de cantidad y grupos de motivos. Por un lado, el Cajón de Valdez presenta comparativamente la mayor frecuencia, representando un $89,79 \%$ de la muestra, especialmente expresado en las improntas de pie humano y rastros de animales. Contrariamente, la cuenca alta del Río Neuquén y la cuenca media del Río Curi-Leuvú, contienen porcentajes menores, representando tan solo el 5,53\% para el primero, y un $4,66 \%$ para el segundo. En este sentido, los recientes relevamientos en la cuenca alta del Neuquén (Cuneo 2017) y los datos aportados en el presente trabajo, nos permiten comenzar a relativizar las construcciones estilísticas formuladas previamente, donde la cuenca Neuquina (Fernández 2000 [1979]; Menghin 1956) era considerada como portadora de un único "estilo" o repertorio de motivos.

En este primer análisis comparativo también resulta destacable remarcar la existencia de similitudes técnicas y morfológicas de las imágenes grabadas en escalas espaciales tan amplias. En términos cualitativos, las diferencias en las técnicas no resultan a priori significativas, incluso teniendo en cuenta la utilización de distintos tipos de rocas soportes que generan efectos figura-fondo relativamente diferentes debido al resultado que deja el surco grabado. A nivel de los grupos de motivos no figurativos, estas similitudes se expresan notablemente en el grupo de motivos de paralelas y los motivos ondulantes opuestos y con eje de simetría axial entre otros (Figura 5), confirmando que el norte neuquino y el extremo sureste de la región del Maule, poseen un horizonte de códigos visuales bien definidos y efectivamente compartidos.

En términos comparativos, los nuevos resultados para la Cuenca del Curí-Leuvú, confirman lo esperable para este espacio en términos de la diversidad de motivos (Barberena 2013) y también de frecuencia de motivos (Barberena et al. 2017). De este modo, comprobamos a una escala más local que el norte neuquino posee una jerarquización espacial en función de la circulación de información (sensu Romero y Re 2014) y que si bien la Cuenca del Curi-Leuvú funcionó como un espacio de relativo riesgo para los grupos humanos debido a su configuración topográfica, un impedimento para la movilidad humana. En cuanto a lo primero, hemos constatado que, en términos generales, la mayor frecuencia y diversidad de códigos visuales compartidos, se encuentran circunscritos y emplazados en espacios intermedios altos, tal como se corrobora para cuenca alta del Río Neuquén y el Cajón de Valdez

En cuanto a lo segundo, y como consecuencia, estas similitudes rupestres nos permiten plantear que los grupos humanos que habitaron dos de las cuencas más importantes del norte de Neuquén durante el Holoceno Tardío transitaron con relativa facilidad los campos altos y estacionales de la Cordillera del Viento e incluso de los Andes, teniendo un elevado conocimiento de sus pasos intermontanos y su ambiente circundante (Figura 3). Particularmente, en el caso de los sitios rupestres aquí analizados que se encuentran a ambos lados de la cordillera del Viento, ubican a tan solo $10 \mathrm{~km}$ en línea recta, de modo tal que es posible cubrir esta distancia en el transcurso de una jornada o dos.

De forma complementaria, este modelo de jerarquización espacial también se verifica positivamente a escala macro regional a partir de los análisis de geoquímica de obsidiana (Barberena et al. 2019; Fernández et al. 2017). Estos trabajos demuestran amplios rangos de movilidad, acceso y usos de espacios altos estacionales, que conectan espacios tan distantes como las cuencas del Barrancas, la cuenca alta del Río Neuquén y la región del Maule para aprovisionarse de materias primas. Sin embargo, en esta línea de evidencia, recientes trabajos apuntan a indagar acerca del tipo de acceso (directo o indirecto) y la frecuencia de las visitas a esta fuente del Maule y otras recientemente descubiertas en el tramo superior del río Varvarco (Barberena et al. 2019).

\section{Consideraciones Finales}

Los resultados aquí expuestos confirman provisoriamente las expectativas de los modelos de uso del espacio propuestos a diferentes escalas para las ocupaciones de cazadores-recolectores del norte neuquino. En este sentido, siguiendo a Barberena et al. (2017), la evidencia rupestre aquí presentada y analizada nos permite afirmar tentativamente que, durante el Holoceno tardío, se corrobora una jerarquización del espacio a determinados mecanismos de interacción social que estructuraron el acceso, uso y tránsito de los distintos espacios biogeográficos. Esta jerarquización se constata provisoriamente con las diferencias en torno a la estructuración espacial del registro rupestre.

En el futuro próximo consideramos necesario profundizar en dos caminos. Por un lado, abordar el problema de las clasificaciones rupestres del norte de Neuquén tal como sugiere Romero (2016), y particularmente en el Cajón de Valdez. Esto nos permitirá reformular las clasificaciones previas y establecer criterios explícitos que permitan abordar en profundidad la variabilidad realmente existente, y lograr comparaciones más ajustadas de los repertorios de motivos tanto de grabados como de pinturas en escalas espaciales amplias. Por otro lado, resta integrar la información aquí presentada respecto de las configuraciones espaciales de la materialidad rupestre con diversas líneas de evidencia arqueológica e información contextual, 
fundamentalmente a escala de la Cuenca del Curi-Leuvú, así como también a escala regional (Gordon et al. 2017).

En suma, la información sobre la distribución espacial de diversos sitios arqueológicos y sus cronologías, así como también el análisis de la procedencia y distribución de las materias primas líticas en el norte neuquino (Barberena et al. 2019; Fernández et al. 2017), nos brindará la posibilidad de complejizar y discutir con mayor resolución el alcance de las hipótesis sobre los patrones de movilidad, uso del espacio, asî como también los resultados sobre la estructuración de la materialidad rupestre. Esto último, nos podría permitir inferir posibles modalidades de apropiación y construcción de paisajes rupestres a lo largo del tiempo por parte de los grupos cazadores-recolectores del CuriLeuvú en particular y del norte de Neuquén en general.

Agradecimientos: Se agradece especialmente al Lic. Adan Hajduk. A mis directores y codirectores de doctorado y al CONICET. A M. Victoria Fernández y Federico L. Scartascini por la lectura crítica del manuscrito. También se agradece especialmente a los funcionarios de Patrimonio de la Provincia de Neuquén por su constante apoyo y a las familias de crianceros trashumantes del CuriLeuvú. Finalmente se agradece a los evaluadores de este trabajo por sus comentarios y aportes.

\section{Referencias Citadas}

Acevedo, A., D. Fiore, N. Franco y M.V. Ocampo 2012-2014. Arte y Espacio. Estructuración de los repertorios de arte rupestre en los Cañadones Yaten Guajen y El Lechuza. (Margen Norte de Río Santa Cruz, Patagonia, Argentina). Mundo de Antes 8:9-33.

Barberena, R. 2013. Biogeografía, competencia y demarcación simbólica del espacio: modelo arqueológico para el norte de Neuquén. Intersecciones en Antropología 14:367-381.

Barberena, R., M.V. Fernández, A.A. Rughini, K. Borrazzo, R. Garvey, G. Lucero, C. Della Negra, G. Romero Villanueva, V. Durán, V. Cortegoso, M. Giesso, C. Klesner, B.L. Macdonald y M.D. Glascock 2019. Deconstructing a complex obsidian 'source-scape' A geoarchaeological and geochemical approach in Northwestern Patagonia. Geoarcheology. 34 (1):30-41

Barberena, R., G. Romero Villanueva, G. Lucero, M.V. Fernández, A.A. Rughini y P. Sosa 2017. Espacios internodales en Patagonia septentrional: biogeografía, información y mecanismos sociales de interacción. Estudios Atacameños 56:57-75.

Belardi, J. y R.A. Goñi 2006. Representaciones rupestres y convergencia poblacional durante momentos tardíos en Santa Cruz (Patagonia argentina). El caso de la meseta del Strobel En Tramas en la Piedra. Producción y Usos del Arte Rupestre editado por D. Fiore y M. M. Podestá, pp. 85-94. World Archaeological Congress, SAA-INAPL, Buenos Aires.

Blanco, J.F., M. De La Maza y M.A. Peñaloza 2015. Memoria inscrita: Arte rupestre de contacto, integración y dominación en el centro-sur de Chile. Boletín del Museo Chileno de Arte Precolombino 20 (2):89-110.

Boschín, M.T. 2009. Tierra de Hechiceros. Arte Indígena de Patagonia Septentrional Argentina. Ediciones Universidad de Salamanca, Salamanca; Servicio de Publicaciones de la Universidad de Córdoba, Córdova.

Burkart R., N. Bárbaro, R. Sánchez y D. Gómez 1999. Eco-regiones de la Argentina. Administración de Parques Nacionales. Secretaria de Recursos Naturales y Desarrollo Sustentable. Presidencia de la Nación, Buenos Aires.

Carden, N. 2008. Imágenes a Través del Tiempo: Arte Rupestre y Construcción Social del Paisaje en la Meseta Central de Santa Cruz. Colección de Tesis Doctorales, Sociedad Argentina de Antropología, Buenos Aires.

Crivelli, M.E. 2006. Frecuencia de creación de sitios de arte rupestre en la cuenca media y superior del río Limay (noroeste patagónico). En Tramas en la Piedra. Producción y Usos del Arte Rupestre, editado por D. Fiore y M.M. Podestá, pp. 63-74. World Archaeological Congress (WAC), SAA, Asociación de Amigos del Instituto Nacional de Antropología, Buenos Aires.

Charlin, J. y L.A. Borrero 2012. Rock art, inherited landscapes, and human populations in Southern Patagonia. En $A$ Companion to Rock Art, editado por J. McDonald y P. Veth, pp. 381-398. Blackwell Publishing, Australia.

Domingo Sanz, I., D. Fiore y K.S. May 2008. Archaeology of Art, Time, Place, Identity. One World Archaeology Series, Vol 55. Left Coast Press, Walmut Creek.

Fernández, J. 2000 [1979]. Las Piedras con Marcas de la Cordillera del Viento. Arte Rupestre en el Departamento Minas, Neuquén, Argentina. Sociedad Argentina de Antropología. Buenos Aires.

Fernández, M.V., R. Barberena, A.A. Rughini, M. Giesso, V. Cortegoso, V. Durán, G. Romero Villanueva, K. Borrazzo, G. Lucero, R. Garvey, B.L. MacDonald y M.D. Glascock 2017. Obsidian geochemistry, geoarchaeology, and lithic technology in northwestern Patagonia (Argentina). Journal of Archeological Science: Reports 13:372-381.

Fiore, D. 2006. Poblamiento de imágenes: arte rupestre y colonización de la Patagonia. Variabilidad y ritmos de cambio en el tiempo y espacio. En Tramas en la Piedra. Producción y Usos del Arte Rupestre, editado por D. Fiore y M.M. Podestá, pp. 43-61. WAC, SAA, Asociación de Amigos del Instituto Nacional de Antropología, Buenos Aires.

Fiore, D. 2007. The economic site of rock art. Concepts on the production of visual images. Rock Art Research 24 (2):149160.

Fiore, D. 2009. La materialidad del arte. Modelos económicos, tecnológicos y cognitivo-visuales. En Perspectivas Actuales en Arqueología Argentina, editado por R. Barberena, K. Borrazo y L.A. Borrero, pp. 121-154. CONICET-IMIHICIHU, Buenos Aires.

Fiore, D. 2011. Materialidad visual y Arqueología de la imagen. Perspectivas conceptuales y propuestas metodológicas desde el sur de Sudamérica. Boletín del Museo Chileno de Arte Precolombino 16 (2):101-119.

Fiore, D. y A. Acevedo 2018. Paisajes rupestres. La identificación de patrones de producción y distribución de arte parietal en escalas espaciales amplias (Cañadón Yaten Guajen, Santa Cruz, Patagonia argentina). Arqueología, 24(2), 177-207. 
González Díaz, E. y A. Folguera 2011. Análisis geomorfológico del tramo medio e inferior de la cuenca de drenaje del río Curri Leuvú, Neuquén. Revista de la Asociación Geológica Argentina 68 (1):17-32.

Gordon, M.F., R. Barberena y V. Bernal (eds.) 2017. El Poblamiento Humano del Norte de Neuquén: Estado Actual del Conocimiento y Perspectivas. Editorial Aspha, Buenos Aires.

Guerello, R. 2006. Geología del Sector Norte de la Fosa de Chos Malal. Provincia de Neuquén. Tesis de Licenciatura. Facultad de Ciencias Exactas y Naturales, Universidad de Buenos Aires, Buenos Aires.

Hammer, Ø. 1999-2018. PAST. Paleontological Statistics. Reference Manual. Version 3.20. Natural History Museum University of Oslo. Acceso online https://folk.uio.no/ohammer/ past/past3manual.pdf

Hajduk, A. y E.M. Cúneo 2009. Representaciones rupestres en la Cuenca del río Curi Leuvú (departamento Chos Malal, Provincia del Neuquén, República Argentina). Informe preliminar. En Arqueología de la Patagonia. Una Mirada desde el Útimo Confín, editado por M. Saleme, F. Santiago, M. Álvarez, E. Piana, M. Vázquez y E. Mansur, pp. 515-526. Editorial Utopías, Ushuaia.

Hajduk, A. y M. Lezcano 2007. Entre invernadas y veranadas: prospecciones arqueológicas en la cuenca superior del río Curi-Leuvú (Norte Neuquino). Actas del XVI Congreso Nacional de Arqueología Argentina, Tomo III, pp. 401-407. San Salvador de Jujuy.

Hajduk, A., A. M. Albornoz y M. Lezcano 2011. Espacio, cultura y tiempo: el corredor bioceánico norpatagónico desde la perspectiva arqueológica. En Cultura y Espacio. Araucanía- Norpatagonia, compilado por P.F Navarro y W. Delrio, pp. 262- 292. IIDyPCaCONICET UNRN, Bariloche. Edición digital. http://iidypca. homestead.com/PublicacionesIIDyPCa/eje_5.pdf

Hajduk, A., P. Novellino, E.M. Cúneo, A.M. Albornoz, C. Della Negra y M.J. Lezcano. 2007. Estado de avance de las investigaciones arqueológicas en el noroeste de la provincia del Neuquén (Departamentos Chos Malal y Minas, República Argentina) y su proyección futura. En Arqueología de FuegoPatagonia. Levantando Piedras, Desenterrando Huesos... y Develando Arcanos, editado por F. Morello, A. Prieto, M. Martinic y G. Bahamonde, pp. 467-477. Ediciones CEQUA, Punta Arenas.

Mcdonald, J. y P. Veth (eds.) 2012. A Companion to Rock Art. Blackwell Publishing, Australia.

Menghin, O. 1957. Estilos de arte rupestre de la Patagonia. Acta Praehistórica I:57-87.

Morales Yamal, A., C. Mella Labraña y P. González Bravo 2017. Arte Rupestre en la Región de Maule. Huellas de un Pasado Desconocido. Consejo Nacional de la Cultura y las Artes, DIBAM, Museo O'Higginiano y de Bellas Artes de Talca, Talca.

Mostny, G. y H. Niemeyer 1983. Arte Rupestre Chileno. Serie Patrimonio Cultural Chileno. Ministerio de Educación, Santiago.

Niemeyer, H y J. Montané 1966. El arte rupestre Indigena de la zona centro sur de Chile. Actas y Memoria del XXXVII
Congreso Internacional de Americanistas, Tomo II, pp. 419452. Buenos Aires.

Niemeyer, F.H. y L. Weisner 1972-1973. Los petroglifos de la Cordillera Andina de Linares (Provincias de Talca y Linares, Chile). Actas del Sexto Congreso de Arqueología Chilena, pp. 405-470, Santiago.

Podestá, M.M., C. Bellelli, R. Labarca, A.M. Albornoz, A. Vasini y E. Tropea 2008. Arte Rupestre en pasos cordilleranos del Bosque Andino Patagónico (El Manso, Región de los Lagos y Provincia de Río Negro, Chile-Argentina). Magallania 36 (2):143-153.

Re, A. y F. Guichón 2009. Densidad y distribución de representaciones rupestres en la meseta del Strobel (Provincia de Santa Cruz). En Arqueología de la Patagonia. Una Mirada desde el Último Confín, editado por M. Salemme, F. Santiago, M. Álvarez, E. Piana, M. Vázquez y E. Mansur, pp. 527-539. Editorial Utopías, Ushuaia.

Romero Villanueva, G. 2016. La clasificación de las pinturas rupestres del noreste de Neuquén, Patagonia septentrional. En Imágenes Rupestres Lugares y Regiones, editado por F. Oliva, A.M. Rocchieti y F.S. Banfi, pp. 441-452. Editorial UNR, Rosario.

Romero Villanueva, G y R. Barberena 2016. Huesos de guanaco pintados de Cueva Huenul 1 (norte del Neuquén, Patagonia septentrional). Relaciones de la Sociedad Argentina de Antropología XLII (2):369-377

Romero Villanueva, G y A. Re 2014. Representaciones rupestres del noreste de Neuquén (Patagonia Septentrional). Primeras tendencias espaciales y temporales. Comechingonia 18:73-92.

Scheinsoh, V. 2011. Rock art information among huntergatherers in Northwest Patagonia: An assessment of environmental and territorial models. En Information and Its Role in Hunter-Gatherer Bands, editado por R. Whallon, W.A. Lovis y K. Hitchcock, pp. 235-248. Cotsen Institute of Archaeology Press, Los Angeles.

Schobinger, J.S. 1956. El arte rupestre de la Provincia del Neuquén. Anales de Arqueología y Etnología XXII:115-227.

Tognonato, C. 1998. Mapa político e hidrográfico de la provincia de Neuquén. Dirección provincial de Catastro e Información Territorial. Provincia del Neuquén.

Troncoso A., F. Moya y M. Basile 2016. Rock art and social networks among hunter gatherers of north-central Chile, Journal of Anthropological Archaeology 42:154-168.

Vargas, F.E. 2015. Petroglifos del Norte Neuquino en la Cuenca del Curi-Leuvú. Un Abordaje desde la Arqueología del Paisaje. Tesis de Licenciatura inédita. Humanidades y Artes, Universidad Nacional de Rosario, Rosario.

Whallon, R. 2011. An introduction to information and its role in hunter-gatherer bands. En Information and Its Role in Hunter-Gatherer Band, editado por R. Whallon, W.A. Lovis, R. K. Hitchcock, pp. 1-27. Costen Institute of Archaeology Press, Los Angeles.

\section{Notas}

\footnotetext{
${ }^{1}$ En el modelo de Barberena (2013) el factor $K$ es retomado de un modelo sobre la productividad potencial de la tierra para el pastoreo actual de ovicápridos, complementado con referencias sobre estudios de la similitud de la dieta entre guanacos y ovinos, lo que permite trasladar este modelo actualístico a tiempos prehispánicos.
}

${ }^{2}$ La similitud morfológica de los diseños facilitó notablemente la tarea de compatibilizar nuestras clasificaciones con la de los autores citados.

${ }^{3}$ El análisis de rarefacción permite comparar la diversidad de una clasificación en muestras de diferentes tamaños. Este 
análisis calcula cuántos taxones (en nuestro caso tipos y grupos de motivos) es esperable encontrar en una muestra con un número total de individuos ( $\mathrm{N}^{\circ}$ motivos) menor (Hammer 1999-2018).

${ }^{4}$ Según hemos constatado en campo, los sitios de la cuenca neuquina se encuentran parcialmente estudiados y publicados. Reviste la misma situación el área del Curi-Leuvú donde los sitios con pinturas aún no han sido estudiados. A futuro esta información permitirá ajustar y testear las hipótesis e interpretaciones vertidas en este trabajo.

${ }^{5}$ En campo corroboramos que en los espacios altos la disponibilidad de agua puede resultar crítica, debido a que se encuentran alejados de los cursos de agua permanentes, y sólo cuentan con pequeños arroyos o vertientes (de naturaleza estacional).
${ }^{6}$ Resta evaluar y contrastar esta hipótesis con contextos arqueológicos y estratigráficos localizados en espacios bajos y cercanos a los cursos de agua anuales.

${ }^{7}$ Debemos remarcar que, si bien hemos integrado nuestra información retomando las categorías y nomenclaturas de tipos y grupos, consideramos que todavía resulta necesario descomponer estas clasificaciones y abordar la posible variabilidad interna de cada categoría, tanto a nivel de los tipos como de grupos de motivos.

${ }^{8}$ Los sitios emblemáticos de la cuenca neuquina, Colo michi có y el Chacay, se localizan en espacios altos por encima de los 2.000 msm (Fernández 2000 [1979]). Esta situación también se presenta en el sitio paso Valdez y los que se encuentran dentro del Cajón de Valdez (Nimeyer y Weisner 1972-1973). 